\title{
Quantification of achiral and chiral methylsulfonyl polychlorinated biphenyl metabolites by column-switching liquid chromatography-atmospheric pressure photoionization-tandem mass spectrometry
}

\author{
Victoria I. Cooper ${ }^{\mathrm{a}}$, Robert J. Letcher ${ }^{\mathrm{b}, \mathrm{c}}$, Rune Dietz ${ }^{\mathrm{d}}$, Christian Sonne ${ }^{\mathrm{d}}$, Charles S. Wong a,e,f,* \\ a University of Alberta, Department of Chemistry, Edmonton, Alberta T6G 2G2, Canada \\ b Environment Canada, National Wildlife Research Centre, Carleton University, Ottawa, Ontario K1A 0H3, Canada

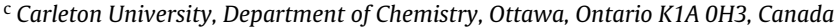 \\ d Aarhus University, Faculty of Science and Technology, Department of Bioscience, Arctic Research Centre, Frederiksborgvej 399, DK-400 Roskilde, Denmark \\ e University of Winnipeg, Richardson College for the Environment, Department of Environmental Studies and Sciences, Winnipeg, Manitoba R3B 2E9, Canada \\ ${ }^{\mathrm{f}}$ University of Winnipeg, Richardson College for the Environment, Department of Chemistry, Winnipeg, Manitoba R3B 2E9, Canada
}

\section{A R T I C L E I N F O}

\section{Article history:}

Received 26 August 2012

Received in revised form 10 October 2012

Accepted 12 October 2012

Available online $\mathrm{xxx}$

\section{Keywords:}

Methylsulfonyl polychlorinated biphenyl metabolites

Atmospheric pressure photoionization

(APPI)

Stereoisomer separation

Environmental analysis

Column-switching liquid chromatography

Tandem mass spectrometry (MS-MS)

\begin{abstract}
A B S T R A C T
An enantioselective heart-cut column-switching liquid chromatography-atmospheric pressure photoionization-tandem mass spectrometry method was developed for the analysis of 25 methylsulfonyl polychlorinated biphenyl metabolites in tissue extracts. Use of a pyrenyl-ethyl silica column in the first dimension enabled separation of all but two pairs of isobaric analytes. Enantioseparation was achieved for 9 out of the 10 atropisomeric analytes using a Chiralpak AD-H amylose-based column within 93 min, resulting in greater chromatographic resolution of enantioseparation over shorter analysis time by up to a factor of three, compared to previous one-dimensional and multi-dimensional gas chromatographybased methods. Precision for concentration and enantiomer fraction measurements was within $11 \%$ and $3 \%$ relative standard deviation, respectively. Limits of detection ranged from 0.01 to $1.73 \mathrm{ng}$ on-column. Meta-congeners had poorer sensitivity (i.e., ng on-column), consistent with existing gas chromatographybased methods. Despite this limitation, the method was successfully applied to the analysis of Greenland sledge dog adipose tissue extracts, which had highly non-racemic residues of 4-methylsulfonyl2,2',3,5',6-pentachlorobiphenyl and $4^{\prime}$-methylsulfonyl-2,2',3,3',4,6'-hexachlorobiphenyl, consistent with past reports in Arctic mammals.
\end{abstract}

(c) 2012 Elsevier B.V. All rights reserved.

\section{Introduction}

Methylsulfonyl polychlorinated biphenyls $\left(\mathrm{MeSO}_{2}-\mathrm{CBs}\right)$ are terminal metabolites of polychlorinated biphenyls (PCBs) biotransformed through cytochrome P-450 (CYP) mediated Phase I processes followed by Phase II/III glutathione conjugation and finally mercapturic acid pathway reactions [1]. $\mathrm{MeSO}_{2}-\mathrm{CBs}$ are persistent, hydrophobic, lipophilic, and bioaccumulative, and can be present in wildlife at concentrations comparable to other legacy organochlorine pollutants, including PCBs [1]. PCB methyl sulfones have toxic effects, such as CYP induction [2,3], interference with aromatase (CYP19) [4], anti-estrogenic activity [5], reduction in blood plasma/target tissue thyroxine levels and observations of increased thyroid gland weight [3], as well as changes in birth

\footnotetext{
* Corresponding author at: Richardson College for the Environment, University of Winnipeg, 515 Portage Ave., Winnipeg, Manitoba R3B 2E9, Canada. Tel.: +1 204786 9335; fax: +1 2047742401 .

E-mail address: wong.charles.shiu@alum.mit.edu (C.S. Wong).
}

weights, survival frequencies and neuro-endocrine development of mink offspring [6]. $\mathrm{MeSO}_{2}$-CBs can elicit effects that differ from their parent compounds; for example, they can inhibit CYP 11B1dependent synthesis of corticosterone in mouse adrenocortical Y1 cells, while parent PCBs do not [7].

As with parent $\mathrm{PCBs}$, some $\mathrm{MeSO}_{2}-\mathrm{CBs}$ that are asymmetrically substituted about the long axis of the molecule are axially chiral, if they have hindered rotation between the two phenyl rings [8]. Of the 837 possible $\mathrm{MeSO}_{2}-\mathrm{CBs}, 456$ are chiral, with 170 that are stable under environmental conditions due to the presence of three or four ortho chlorine atoms [9]. However, only about $60 \mathrm{MeSO}_{2}-\mathrm{CB}$ congeners are frequently detected in wildlife and humans [1]. Of those, only ten are chiral congeners existing as pairs of atropisomers, hereafter referred to as enantiomers. Nonracemic residues of $\mathrm{MeSO}_{2}-\mathrm{CBs}$ in environmental media, typically extracted through standard methods for hydrophobic organic compounds (e.g., Soxhlet, pressurized solvent extraction) and purified through appropriate cleanup procedures (e.g., normal-phase column fractionation), have been observed in various wildlife species and humans [10-13], caused at least in part by enantioselective 
biotransformation [14,15]. Although it is currently unknown if $\mathrm{MeSO}_{2}-\mathrm{CBs}$ have enantioselective toxic effects, the enantiomers of their parent PCBs are known to have differential effects in inducing xenobiotic-metabolizing enzymes [16], accumulating uroporphyrin [17], and causing neurotoxicity [18] in part from affecting $\mathrm{Ca}^{2+}$-sequestration in the cerebellum [19]. Thus, it is likely that $\mathrm{MeSO}_{2}$-CB stereoisomers also have enantioselective toxicity.

Quantification of $\mathrm{MeSO}_{2}-\mathrm{CBs}$ is important for proper risk assessment, due to the presence and toxicity of these metabolites. This includes enantioselective analysis, given expected differences in toxicity between individual enantiomers, which could also be useful in understanding environmental biochemical processes [8]. Gas chromatography (GC), typically coupled either to electron capture detection (ECD) or mass spectrometry (MS), is currently the method of choice for trace-level $\mathrm{MeSO}_{2}-\mathrm{CB}$ analysis [1], with enantiomer analysis accomplished using enantioselective columns [10,11,13]. Multidimensional GC has also been used [20]. However, these techniques have some key disadvantages [8]. The first is long run times, on the order of $2-5 \mathrm{~h}$. This is due in part to limited maximum temperature limits of enantioselective columns $\left(\leq \mathrm{ca} .250^{\circ} \mathrm{C}\right.$ compared to ca. $375^{\circ} \mathrm{C}$ for non-enantioselective polysiloxane columns), leading to broad peaks and reduced sensitivity. In addition, resolution of some chiral $\mathrm{MeSO}_{2}-\mathrm{CB}$ enantiomers, such as meta- and paramethylsulfonyl 2,2',3,5',6-pentachlorobiphenyl (CB95) [10,11,13] has remained elusive.

Liquid chromatography (LC) has been used to separate chiral $\mathrm{MeSO}_{2}-\mathrm{CBs}$, but mostly on a semi-preparative scale [21] to determine absolute configuration of individual enantiomers. No attempt to date has used $\mathrm{LC}$ for trace-level $\mathrm{MeSO}_{2}-\mathrm{CB}$ quantification. Although GC is generally an easier and more efficient technique for analysis of hydrophobic semivolatile analytes, enantioselective LC is well-established. Accordingly, we hypothesized that LC may be a suitable alternative, if coupled with a tandem mass spectrometer (MS-MS) for sensitive and selective detection. Indeed, baseline resolution of enantiomers has been reported for some PCBs [22] and $\mathrm{MeSO}_{2}$-CBs [21] using enantioselective LC. While nonpolar analytes are not ionizable by electrospray ionization, they are compatible with alternative ionization techniques, such as atmospheric pressure photoionization (APPI), which is of particular interest given that it is generally less susceptible to matrix effects than other LC-based ionization techniques $[23,24]$.

The goal of this study was to develop an HPLC-APPI-MS-MS method for congener and enantiomer analysis of achiral and chiral methylsulfonyl PCB metabolites. As proof of principle, this method is applied to the measurement of $\mathrm{MeSO}_{2}-\mathrm{CBs}$ in extracts of sledge dog (Canis familiaris) adipose tissues. Enantiomer-specific analysis allows more complete characterization of metabolic processes and environmental fate. To our knowledge, this is the first quantitative LC-based method for $\mathrm{MeSO}_{2}-\mathrm{CB}$ measurement, as well as the first application of APPI to analysis of these compounds.

\section{Experimental}

\subsection{Chemicals and reagents}

Analytical standards of 25 achiral and racemic meta- and parasubstituted $\mathrm{MeSO}_{2}$-CBs (Table 1 ), named as previously defined [25], were purchased from Accustandard (New Haven, CT, USA). These comprise most of the congeners commercially available, and most of those observed in the environment [1]. A methylated $\mathrm{MeSO}_{2}-\mathrm{CB}, 3-\mathrm{MeSO}_{2}-4$-Me-2', $3^{\prime}, 4^{\prime}, 5,5^{\prime}$-pentachlorobiphenyl, was purchased from Cambridge Isotope Laboratories (Andover, MA, USA) as an internal standard. All analytical standards were $>97 \%$ purity.
Table 1

Methylsulfonyl polychlorinated biphenyls $\left(\mathrm{MeSO}_{2}-\mathrm{CBs}\right)$ targeted in this study. Stable chiral congeners in boldface. Abbreviation in parentheses used in figures and other tables. Naming convention as per [25].

\begin{tabular}{|c|c|}
\hline $\mathrm{MeSO}_{2}-\mathrm{CB}$ & Full name \\
\hline $3^{\prime}-\mathrm{MeSO}_{2}-\mathrm{CB} 49\left(3^{\prime}-49\right)$ & $3^{\prime}-\mathrm{MeSO}_{2}-2,2^{\prime} 4,5^{\prime}$-tetrachlorobiphenyl \\
\hline $4^{\prime}-\mathrm{MeSO}_{2}-\mathrm{CB} 49\left(4^{\prime}-49\right)$ & $4^{\prime}-\mathrm{MeSO}_{2}-2,2^{\prime} 4,5^{\prime}$-tetrachlorobiphenyl \\
\hline $3-\mathrm{MeSO}_{2}-\mathrm{CB} 52(3-52)$ & 3-MeSO ${ }_{2}-2,2^{\prime}, 5,5^{\prime}$-tetrachlorobiphenyl \\
\hline $4-\mathrm{MeSO}_{2}-\mathrm{CB} 52(4-52)$ & 4-MeSO $2-2,2^{\prime}, 5,5^{\prime}$-tetrachlorobiphenyl \\
\hline $4-\mathrm{MeSO}_{2}-\mathrm{CB} 64$ (4-64) & 4-MeSO $2-2,3,4^{\prime}, 6$-tetrachlorobiphenyl \\
\hline 3- $\mathrm{MeSO}_{2}-\mathrm{CB} 70(3-70)$ & 3-MeSO $2-2,3^{\prime}, 4^{\prime}, 5$-tetrachlorobiphenyl \\
\hline $4-\mathrm{MeSO}_{2}-\mathrm{CB} 70(4-70)$ & 4-MeSO $2-2,3^{\prime}, 4^{\prime}, 5$-tetrachlorobiphenyl \\
\hline $3^{\prime}-\mathrm{MeSO}_{2}-\mathrm{CB} 87\left(3^{\prime}-87\right)$ & $3^{\prime}-\mathrm{MeSO}_{2}-2,2^{\prime}, 3,4,5^{\prime}$-pentachlorobiphenyl \\
\hline $4^{\prime}-\mathrm{MeSO}_{2}-\mathrm{CB} 87\left(4^{\prime}-87\right)$ & $4^{\prime}-\mathrm{MeSO}_{2}-2,2^{\prime}, 3,4,5^{\prime}$-pentachlorobiphenyl \\
\hline 5-MeSO 2 -CB91 (5-91) & 5-MeSO ${ }_{2}-2,2^{\prime}, 3,4^{\prime}, 6$-pentachlorobiphenyl \\
\hline $4-\mathrm{MeSO}_{2}$-СB91 (4-91) & 4-MeSO ${ }_{2}-2,2^{\prime}, 3,4^{\prime}, 6$-pentachlorobiphenyl \\
\hline $3^{\prime}-\mathrm{MeSO}_{2}-\mathrm{CB95}\left(3^{\prime}-95\right)$ & $3^{\prime}-\mathrm{MeSO}_{2}-2,2^{\prime}, 3,5^{\prime}, 6$-pentachlorobiphenyl \\
\hline $4^{\prime}-\mathrm{MeSO}_{2}$-CB95 (4'-95) & $4^{\prime}$-MeSO ${ }_{2}-2,2^{\prime}, 3,5^{\prime}, 6$-pentachlorobiphenyl \\
\hline $3^{\prime}-\mathrm{MeSO}_{2}-\mathrm{CB} 101\left(3^{\prime}-101\right)$ & $3^{\prime}-\mathrm{MeSO}_{2}-2,2^{\prime}, 4,5,5^{\prime}$-pentachlorobiphenyl \\
\hline $4^{\prime}-\mathrm{MeSO}_{2}-\mathrm{CB} 101\left(4^{\prime}-101\right)$ & $4^{\prime}-\mathrm{MeSO}_{2}-2,2^{\prime}, 4,5,5^{\prime}$-pentachlorobiphenyl \\
\hline $5-\mathrm{MeSO}_{2}-\mathrm{CB} 110(5-110)$ & 5-MeSO $2-2,3,3^{\prime}, 4^{\prime}, 6$-pentachlorobiphenyl \\
\hline $4-\mathrm{MeSO}_{2}-\mathrm{CB} 110(4-110)$ & 4- $\mathrm{MeSO}_{2}-2,3,3^{\prime}, 4^{\prime}, 6$-pentachlorobiphenyl \\
\hline $5^{\prime}-\mathrm{MeSO}_{2}-\mathrm{CB} 132\left(5^{\prime}-132\right)$ & $5^{\prime}-\mathrm{MeSO}_{2}-2,2^{\prime}, 3,3^{\prime}, 4,6^{\prime}$-hexachlorobiphenyl \\
\hline $4^{\prime}-\mathrm{MeSO}_{2}-\mathrm{CB} 132\left(4^{\prime}-132\right)$ & $4^{\prime}-\mathrm{MeSO}_{2}-2,2^{\prime}, 3,3^{\prime}, 4,6^{\prime}$-hexachlorobiphenyl \\
\hline $3^{\prime}-\mathrm{MeSO}_{2}-\mathrm{CB} 141\left(3^{\prime}-141\right)$ & $3^{\prime}-\mathrm{MeSO}_{2}-2,2^{\prime}, 3,4,5,5^{\prime}$-hexachlorobiphenyl \\
\hline $4^{\prime}-\mathrm{MeSO}_{2}-\mathrm{CB} 141\left(4^{\prime}-141\right)$ & $4^{\prime}-\mathrm{MeSO}_{2}-2,2^{\prime}, 3,4,5,5^{\prime}$-hexachlorobiphenyl \\
\hline $5-\mathrm{MeSO}_{2}-\mathrm{CB} 149$ (5-149) & 5 - MeSO $_{2}-2,2^{\prime}, 3,4^{\prime}, 5^{\prime}, 6$-hexachlorobiphenyl \\
\hline $4-\mathrm{MeSO}_{2}-\mathrm{CB} 149$ (4-149) & 4-MeSO 2 -2,2',3,4',5',6-hexachlorobiphenyl \\
\hline $5^{\prime}-\mathrm{MeSO}_{2}-\mathrm{CB} 174\left(5^{\prime}-174\right)$ & $5^{\prime}-\mathrm{MeSO}_{2}-2,2^{\prime}, 3,3^{\prime}, 4,5,6^{\prime}$-heptachlorobiphenyl \\
\hline $4^{\prime}-\mathrm{MeSO}_{2}-\mathrm{CB} 174\left(4^{\prime}-174\right)$ & $4^{\prime}-\mathrm{MeSO}_{2}-2,2^{\prime}, 3,3^{\prime}, 4,5,6^{\prime}$-heptachlorobiphenyl \\
\hline
\end{tabular}

Methanol, ethanol, isopropanol, hexanes and heptanes were obtained from Fisher Scientific Inc. (Ottawa, ON, Canada), while toluene was obtained from Sigma-Aldrich (Oakville, ON, Canada). All solvents were HPLC-grade and filtered through $2 \mu \mathrm{m}$ polytetrafluoroethylene membrane filters (Chromatographic Specialties, Hamilton, ON, Canada) prior to use. De-ionized water was purified to $18 \mathrm{M} \Omega \mathrm{cm}$ using an Ultrapure Nanopore filtration system (Barnsteam/Thermolyne, Dubuque, IA, USA) and subsequently filtered through $2 \mu \mathrm{m}$ Whatman nylon membrane filters (Whatman Inc., Piscataway, NJ, USA) immediately prior to use. All reagents were used as received.

\subsection{Instrumental analysis}

\subsubsection{Column-switching liquid chromatography}

Column-switching liquid chromatography was performed on an Agilent 1100 HPLC (Agilent Technologies, Palo Alto, CA, USA), with samples thermostatted at $4{ }^{\circ} \mathrm{C}$ prior to injection of $20 \mu \mathrm{L}$. Achiral congeners were first separated by degree of ortho-chlorination using a Cosmosil 5-PYE column (2-(1-pyrenyl)ethyl derivatized silica, $4.6 \times 250 \mathrm{~mm} \times 5 \mu \mathrm{m}$, Nacalai Tesque, Tokyo, Japan) with matching guard column $(4.6 \times 10 \mathrm{~mm} \times 5 \mu \mathrm{m})$ [26]. The second dimension separated enantiomers using a Chiralpak AD-H column (amylose tris-(3,5-dimethylphenylcarbamate) derivatized silica, $4.6 \times 250 \mathrm{~mm} \times 5 \mu \mathrm{m}$; Chiral Technologies Inc., West Chester, PA, USA) with matching guard column $(4.0 \times 10 \mathrm{~mm} \times 5 \mu \mathrm{m})$. Initial methods development used a Chiralpak AD column with the same dimensions as the Chiralpak AD-H, but with $10 \mu \mathrm{m}$ particles, as well as a number of non-enantioselective and enantioselective columns as detailed in Supplemental Information.

Isocratic elution at $1.0 \mathrm{~mL} / \mathrm{min}$ was achieved with $95: 5$ heptanes:50-50 methanol-ethanol by volume at $12.5^{\circ} \mathrm{C}$. An integrated 10-port diverter valve was employed to change the flow path throughout the chromatographic run (Fig. 1). In configuration $\mathrm{A}$, the mobile phase went through the PYE column, then through the Chiralpak AD-H and on to the ionization source. In configuration $\mathrm{B}$, the mobile phase went through the PYE column, now connected directly to the ion source, while the Chiralpak AD-H column was 


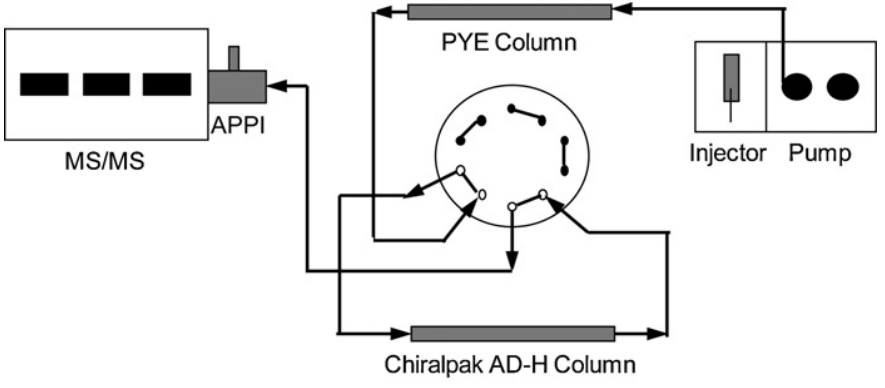

CONFIGURATIONA

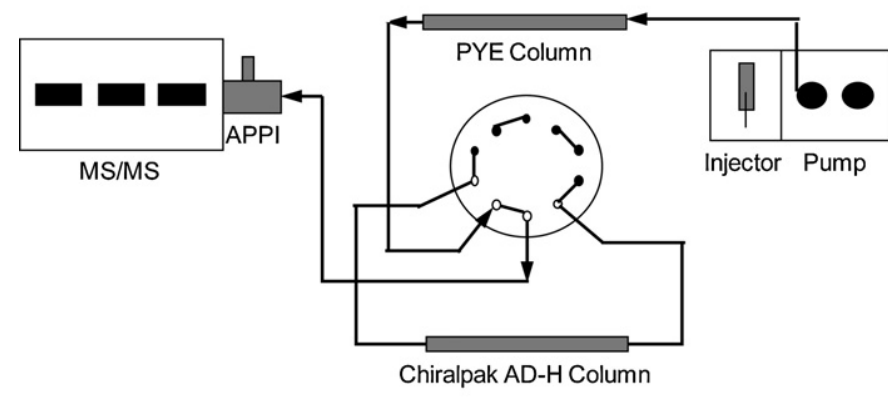

CONFIGURATION B

Fig. 1. Schematic representation of column-switching liquid chromatography. Solid lines with arrows indicate direction of solvent flow. Lines without arrows represent closed loops with no solvent flow. Open circles in valve represent ports connected to tubing. Filled circles in valve represent plugged ports.

connected to a blocked port and had no flow. The valve was programmed as follows: 0-14.6 min, A; 14.6-23.8 min, B; 23.8-91 min, A. From 0 to $14.6 \mathrm{~min}$ the chiral $\mathrm{MeSO}_{2}-\mathrm{CBs}$, which eluted from the PYE column first, were directed onto the Chiralpak AD-H for enantioselective separation. Some multiple ortho-substituted achiral congeners also eluted and were necessarily directed on to the enantioselective column. From 14.6 to $23.8 \mathrm{~min}$, the remaining achiral congeners eluted from the PYE column. At $23.8 \mathrm{~min}$, the flow through the Chiralpak $\mathrm{AD}-\mathrm{H}$ was resumed, and all remaining analytes were detected after elution from the second-dimension column.

\subsubsection{APPI and $M S / M S$}

A QTrap hybrid linear ion trap-triple quadrupole mass spectrometer with a first generation PhotoSpray source (Applied Biosystems/MDS Sciex, Foster City, CA, USA) was used for quantification in multiple reaction monitoring (MRM) mode. The APPI source was operated in negative ion mode with either a $\mathrm{Kr}$ (10.0/10.6 eV, Heraeus Noblelight GmbH, Hanau, Germany) or an Ar (11.8 eV, Perkin Elmer Optoelectronics, Salem, MA, USA) gas discharge lamp, with current held constant between 0.70 and $0.85 \mathrm{~mA}$. Dry, purified air was used as curtain, nebulizer, and auxiliary gases, while nitrogen (>99.5\%) was used as lamp and collisionally activated dissociation (CAD) gas. The Ar used for CAD gas in some ionization experiments was $>99.998 \%$ purity.

Ionization parameters were optimized by infusion of individual $1.0 \mu \mathrm{g} / \mathrm{mL}$ solutions in hexanes at $10-20 \mu \mathrm{L} / \mathrm{min}$ with $0.5 \mathrm{~mL} / \mathrm{min}$ mobile phase flow, typically in triplicate. Toluene dopant was delivered as needed using an external syringe pump (Harvard Apparatus, Holliston, MA, USA). Optimized ion source parameters were: curtain gas 0.7 bar, ion spray voltage $-1100 \mathrm{~V}$, nebulizer gas 6.2 bar, auxiliary gas 0.7 bar, probe axial position $2.5 \mathrm{~mm}$, and probe lateral position $7.0 \mathrm{~mm}$. For the Ar lamp, a lamp gas setting of $3.0 \mathrm{~L} / \mathrm{min}$ and a heated nebulizer temperature of $250^{\circ} \mathrm{C}$ with no dopant was optimal. Conversely, for the Kr lamp, a lamp gas flow of $1.0 \mathrm{~L} / \mathrm{min}$
Table 2

Optimal negative-mode atmospheric pressure photoionization (APPI) MS-MS parameters for multiple reaction monitoring (MRM) of $\mathrm{MeSO}_{2} \mathrm{CBs}$, by chlorine substitution level. All congeners formed a $[\mathrm{M}-\mathrm{Cl}+\mathrm{O}]^{-}$precursor ion. $[\mathrm{M}-98]^{-}=\left[\mathrm{M}-\mathrm{Cl}+\mathrm{O}-\mathrm{CH}_{3} \mathrm{SO}_{2}\right]^{-}$product ion; $[\mathrm{M}-126]^{-}=\left[\mathrm{M}-\mathrm{Cl}+\mathrm{O}-\mathrm{CH}_{3} \mathrm{SO}_{2}-\mathrm{CO}\right]^{-}$product ion. Internal standard (IS): 3-

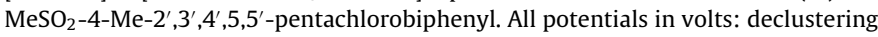
potential (DP), entrance potential (EP), collision energy (CE), collision cell entrance potential (CEP), collision cell exit potential (CXP).

\begin{tabular}{|c|c|c|c|c|c|c|}
\hline & MRM & DP & EP & $\mathrm{CE}$ & CEP & CXP \\
\hline Tetra $[\mathrm{M}-126]^{-}$ & $349 \rightarrow 242$ & -50 & -9 & -40 & -21 & -2 \\
\hline Tetra $[\mathrm{M}-98]^{-}$ & $349 \rightarrow 270$ & -55 & -9 & -35 & -21 & -4 \\
\hline Penta [M-126] $]^{-}$ & $385 \rightarrow 278$ & -50 & -7 & -40 & -14 & -1.5 \\
\hline Penta $[\mathrm{M}-98]^{-}$ & $385 \rightarrow 306$ & -50 & -7 & -40 & -22 & -2 \\
\hline IS [M-98]- & $399 \rightarrow 320$ & -60 & -8 & -35 & -22 & -1.5 \\
\hline Hexa [M-126] ${ }^{-}$ & $419 \rightarrow 312$ & -45 & -9 & -40 & -14 & -2 \\
\hline Hexa [M-98] $]^{-}$ & $419 \rightarrow 340$ & -45 & -9 & -40 & -23 & -2 \\
\hline Hepta $[\mathrm{M}-126]^{-}$ & $453 \rightarrow 346$ & -60 & -8 & -30 & -24 & -1.5 \\
\hline Hepta [M-98] ${ }^{-}$ & $453 \rightarrow 374$ & -60 & -8 & -30 & -24 & -1.5 \\
\hline
\end{tabular}

and source temperature of $400{ }^{\circ} \mathrm{C}$ with toluene dopant delivered at $100 \mu \mathrm{L} / \mathrm{min}$ (10\% of the LC flow) was optimal. Unless otherwise stated, these latter conditions were employed for all flow injection and infusion experiments with this lamp. For all analytes, a CAD gas setting of 0.34 psi was optimal. A dwell time of $10 \mathrm{~ms}$ was employed, and remaining ionization parameters varied by transition (Table 2).

\subsubsection{Processing of environmental samples}

To illustrate the utility of this method, $\mathrm{MeSO}_{2}-\mathrm{CB}$ concentrations and enantiomer compositions were determined in extracts of sledge dog adipose tissues, from a multi-generational feeding study investigating the toxicokinetics and effects of persistent halogenated contaminants on a model Arctic mammalian species [27]. As described in detail elsewhere [27-30], captive dogs were fed either wild minke whale (Balaenoptera acutorostrata) blubber with existing unspiked chemical contamination (exposed cohort), or pork fat (control cohort) for two years to simulate natural exposure in a controllable manner. A subset of dogs were bred with a single, control diet-fed male to produce two litters of offspring such that the first had reached sexual maturity while the second was still pre-weaning. All pups received only mothers's milk pre-weaning, to study xenobiotic maternal transfer. Post-weaning, both sets of offspring were combined into their respective control and exposed groups. Sample processing is described elsewhere [31] and summarized in Supplemental Information. $\mathrm{MeSO}_{2}-\mathrm{CBs}$ were not quantified in the original study [32].

\subsection{Data analysis}

Peak areas from flow injection analysis experiments were integrated using Analyst version 1.4.2 software (Applied Biosystems/MDS Sciex, Foster City, CA, USA). All analyte peaks in chromatographic runs were integrated with PeakFit version 4.06 software (Systat Software, Inc., San Jose, CA, USA), using an exponentially modified Gaussian function. Deconvolution of closely eluting peaks results in more accurate results than dropping baselines (i.e., typical processing by commercial chromatographic software) [33], particularly for the tailing peaks we observed. The "Vary Widths" option was used, as appropriate for modeling peaks under PeakFit with half-width asymmetry between 0.45 and 2.225 as observed here given isocratic eluent conditions. Enantiomer fractions [34] to quantify enantiomer composition were calculated:

$E F=\frac{(E 1)}{(E 1)+(E 2)}$

where $E 1$ and $E 2$ are the first- and second-eluting enantiomer concentrations, respectively, as elution orders of the 
(+)- and (-)-enantiomers are unknown. EFs of racemic standards were $($ mean $\pm \sigma): 0.487 \pm 0.004$ for $4-\mathrm{MeSO}_{2}-\mathrm{CB} 91,0.49 \pm 0.01$ for $3-\mathrm{MeSO}_{2}-\mathrm{CB} 95,0.53 \pm 0.02$ for $4-\mathrm{MeSO}_{2}-\mathrm{CB} 95,0.48 \pm 0.01$ for $4-\mathrm{MeSO}_{2}-\mathrm{CB} 132,0.518 \pm 0.007$ for $4-\mathrm{MeSO}_{2}-\mathrm{CB} 149$, and $0.541 \pm 0.005$ for $4-\mathrm{MeSO}_{2}-\mathrm{CB} 174$.

Statistical analysis was performed using Prism version 4.00 (GraphPad Software, San Diego, CA, USA). All statistical tests for analytical methodology development were done using $t$-tests or one-way ANOVAs with Tukey's multiple comparison test, as applicable. Kruskal-Wallis tests were used for comparing sledge dog concentrations and EFs, with a significance level of 0.05 in all cases. Error estimates are $\sigma$ unless otherwise indicated.

\section{Results and discussion}

\subsection{APPI ionization}

The highest intensity peak with APPI in negative mode was $\left[\mathrm{M}-\mathrm{Cl}+\mathrm{O}^{-}\right.$. No $\mathrm{M}^{\bullet-}$ ions were found. Phenoxide precursor ions are consistent with previous observations for a variety of halogenated aromatic compounds ionized by negative-mode APPI [35], possibly by ipso-substitution with $\left[\mathrm{M}+\mathrm{O}_{2}\right]^{\bullet}$ as the intermediate radical anion [36]. Electron capture negative ionization (ECNI) of $\mathrm{MeSO}_{2}-\mathrm{CBs}$ (i.e., GC-MS analysis) can also produce these ions $[37,38]$. No ionization was observed for APPI in positive mode. While negative-mode atmospheric pressure chemical ionization (APCI) produced similar ionization patterns as APPI $(-)$, intensities were at least two orders of magnitude lower, so no further APCI work was done here.

Ionization conditions were assessed with the $[\mathrm{M}-\mathrm{Cl}+\mathrm{O}]^{-}$ion using the optimized LC eluent composition (Section 2.2) for both $\mathrm{Kr}$ and $\mathrm{Ar}$ APPI lamps, to determine which would be more useful for analysis of $\mathrm{MeSO}_{2}-\mathrm{CBs}$. For the $\mathrm{Kr}$ lamp, only toluene and anisole were effective dopants. However, anisole produced a fivefold lower response for $\mathrm{MeSO}_{2}-\mathrm{CBs}$ compared to toluene. Acetone, bromobenzene, dichloromethane, and 1\% 1,3-dibromobenzene in toluene all produced very poor results (data not shown). Toluene had a two-fold increase in signal at a flow rate of up to $10 \%$ of the mobile phase flow compared to no dopant. No further signal increase was found with higher percentages of toluene dopant flow rates, likely due to an increase in dopant neutralization reactions at higher flow [39]. In contrast, toluene dopant, at $100 \mu \mathrm{L} / \mathrm{min}$ with $1 \mathrm{~mL} / \mathrm{min}$ optimized mobile phase, provided little increase in signal-to-noise ratios for $\mathrm{MeSO}_{2}-\mathrm{CBs}$ with the Ar lamp.

The higher-energy Ar lamp provided less background noise, as well as better ionization of the low ionization energy $(9.93 \mathrm{eV}$, [24]) heptane-based mobile phase, and therefore better ionization of $\mathrm{MeSO}_{2}$-CBs (Figure S1) due to the solvent's self-doping effect. Further optimization on the Ar lamp resulted in its adoption for quantification with parameters as described in Section 2.2.2, which were also optimal for the $\mathrm{Kr}$ lamp. The optimal temperature was affected by the mobile phase composition, but none of the other parameters varied with eluent. For example, ionization efficiency increased approximately three-fold when the eluent polar modifier was switched from ethanol to methanol in both reversed-phase and normal phase. However, a 50:50 mixture of these solvents, as in the optimized eluent, produced a level of sensitivity similar to that with methanol alone. A small decrease in ionization efficiency (less than two-fold) was observed with increasing alcohol content in normal phase, consistent with the enantioselective LC-APPI-MS analysis of propranolol [40]. Ionization efficiency was optimal at $0.2 \mathrm{~mL} / \mathrm{min}$ eluent flow rate and decreased proportionally at higher flows (e.g. by $27 \%$ of optimal levels at $0.75 \mathrm{~mL} / \mathrm{min}$ ), in agreement with observations that APPI is most sensitive $<0.5 \mathrm{~mL} / \mathrm{min}$ [41]. However, at the final effluent flow rate of $1.0 \mathrm{~mL} / \mathrm{min}$ selected in chromatographic method development (Section 3.3), the decreased ionization efficiency from less-than-optimal flow rates was more than offset by increase in signal due to decreased band broadening.

\subsection{Tandem mass spectrometry}

For the majority of the analytes, the most abundant ion was the $[\mathrm{M}-\mathrm{Cl}+\mathrm{O}]^{-}$precursor (Table 3). With a few exceptions, the most abundant product ion for meta-substituted congeners arose from the loss of the methylsulfonyl group to form the $\left[\mathrm{M}-\mathrm{Cl}+\mathrm{O}-\mathrm{CH}_{3} \mathrm{SO}_{2}\right]^{-}$ion $\left([\mathrm{M}-98]^{-}\right)$, while that for para-substituted $\mathrm{MeSO}_{2}$-CBs was from the loss of an additional carbonyl group to form the $\left[\mathrm{M}-\mathrm{Cl}+\mathrm{O}-\mathrm{CH}_{3} \mathrm{SO}_{2}-\mathrm{CO}\right]^{-}$product ion $\left([\mathrm{M}-126]^{-}\right)$. In addition, the cumulative absolute intensities (MCA mode) over $1 \mathrm{~min}$ under the same conditions was generally higher for para congeners than meta congeners for both precursor and product ions, with only a few exceptions (Figure S3). Fragmentation was unaffected by solvent used.

These observations were consistent with likely fragmentation mechanisms. Although rearrangement of the methylsulfonyl group may occur during fragmentation of $\mathrm{MeSO}_{2}-\mathrm{CBs}$, the observation of a peak at $m / z 79$ corresponding to the intact $\mathrm{CH}_{3} \mathrm{SO}_{2}$ group for some analytes suggests that the entire moiety is lost, leaving behind the oxygen atom added during primary ionization. The different product ions observed may suggest that this oxygen atom remains in the ortho or meta position for meta-MeSO $\mathrm{S}_{2}-\mathrm{CBs}$, and in the meta position for para- $\mathrm{MeSO}_{2}$-CBs. Furthermore, since the oxygen is likely added via an ipso-substitution mechanism involving an unconjugated intermediate with chlorine and peroxide groups attached to the same carbon atom [42], the oxygen must add at the site of a chlorine substituent. If the oxygen does not migrate during ionization or fragmentation, then the para- $\mathrm{MeSO}_{2}-\mathrm{CBs}$ undergoes oxygen substitution at the meta position, and the meta-MeSO $2-\mathrm{CBs}$ at the ortho position due to the 2,5-dichloro or 2,3,6-trichloro substitution pattern present in all environmentally relevant $\mathrm{MeSO}_{2}-\mathrm{CBs}$ [1]. Steric hindrance would therefore arise due to interactions between the ortho oxygen and the other ortho substituents for meta-substituted $\mathrm{MeSO}_{2}-\mathrm{CBs}$, making them less stable and lower in abundance. Indeed, fragments for which the methylsulfonyl group remains intact have a greater number of resonance structures, and therefore greater stability of para isomers [38]. For the chiral pentachlorinated congeners, both $3^{\prime}-\mathrm{MeSO}_{2}-\mathrm{CB} 95$ and $4^{\prime}-\mathrm{MeSO}_{2}-\mathrm{CB} 95$ had much lower responses than $5-\mathrm{MeSO}_{2}-\mathrm{CB} 91$ and $4-\mathrm{MeSO}_{2}-\mathrm{CB} 91$, respectively. The $\mathrm{CB} 91$ metabolites have a 2,3,6-trichloro substitution pattern on the $\mathrm{MeSO}_{2}$-bearing ring and a chlorine substituent in the para position on the opposite ring, unlike the CB95 metabolites which have 2,5-dichloro substitution on the $\mathrm{MeSO}_{2}$ ring and no opposite para chlorine. Both of these structural characteristics have previously been suggested to have an effect on the relative abundances of $\mathrm{MeSO}_{2}$-CB fragment ions using ECNI [38].

Final conditions for tandem mass spectrometry by MRM are presented in Tables 2 and 3. Optimal ranges for most of these parameters were generally quite similar between isobaric analytes, so dynamic MRM, which was not possible given software limitations, was not necessary. Tolerances in MRM transition ratios, for quality assurance/quality control purposes (Table 3 ) depended on intensities compared to the base peaks as per European Union guidelines for LC-MS-MS analysis [43]. A dwell time of $10 \mathrm{~ms}$ was used in all transitions. However, due to the large widths of the chromatographic peaks produced, an increase in dwell time is recommended, to decrease noise observed across the peaks in this study.

\subsection{Chromatography}

The optimal chromatographic conditions were achieved using two-dimensional heart-cut liquid chromatography, with 
Table 3

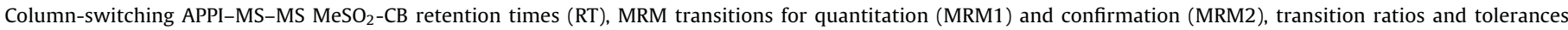

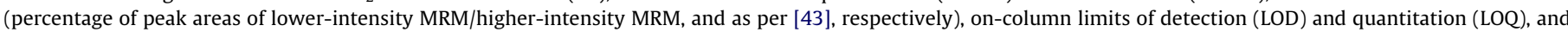

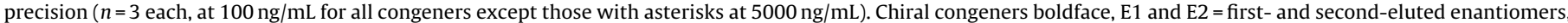
respectively. Internal standard (IS): 3- $\mathrm{MeSO}_{2}-4-\mathrm{Me}-2^{\prime}, 3^{\prime}, 4^{\prime}, 5,5^{\prime}$-pentachlorobiphenyl.

\begin{tabular}{|c|c|c|c|c|c|c|c|c|}
\hline $\mathrm{MeSO}_{2}-\mathrm{CB}$ & $\mathrm{RT}(\min )$ & MRM1 & MRM2 & Ratio (\%) & Tolerance (\%) & LOD (ng) & LOQ (ng) & Precision (\% RSD) \\
\hline $3^{\prime}-49^{*}$ & 44.2 & $349 \rightarrow 270$ & - & - & - & 1.74 & 5.80 & 38.1 \\
\hline $4^{\prime}-49$ & 58.6 & $349 \rightarrow 242$ & $349 \rightarrow 270$ & 90.9 & 20 & 0.05 & 0.16 & 2.8 \\
\hline $3-52+4-64$ & 55.0 & $349 \rightarrow 242$ & $349 \rightarrow 270$ & 28.6 & 25 & 0.01 & 0.04 & 5.0 \\
\hline $4-52$ & 69.6 & $349 \rightarrow 242$ & $349 \rightarrow 270$ & 66.7 & 20 & 0.03 & 0.10 & 4.9 \\
\hline $3-70$ & 18.5 & $349 \rightarrow 270$ & $349 \rightarrow 242$ & 76.9 & 20 & 0.03 & 0.11 & 2.6 \\
\hline $4-70$ & 19.2 & $349 \rightarrow 242$ & $349 \rightarrow 270$ & 30.3 & 25 & 0.02 & 0.08 & 10.3 \\
\hline $3^{\prime}-87+4-110$ & 15.0 & $385 \rightarrow 278$ & $385 \rightarrow 306$ & 28.6 & 25 & 0.03 & 0.10 & 2.9 \\
\hline $4^{\prime}-87$ & 16.8 & $385 \rightarrow 278$ & $385 \rightarrow 306$ & 66.7 & 25 & 0.11 & 0.39 & 1.9 \\
\hline E1+E2-5-91 & 51.7 & $385 \rightarrow 306$ & $385 \rightarrow 278$ & 10.2 & 30 & 0.03 & 0.10 & 3.0 \\
\hline E1-4-91 & 37.2 & $385 \rightarrow 278$ & $385 \rightarrow 306$ & 25.0 & 25 & 0.03 & 0.09 & 3.9 \\
\hline E2-4-91 & 38.4 & $385 \rightarrow 278$ & $385 \rightarrow 306$ & 25.0 & 25 & 0.03 & 0.10 & 4.9 \\
\hline E1-3'-95* & 33.1 & $385 \rightarrow 306$ & - & - & - & 0.94 & 3.13 & 4.7 \\
\hline E2-3'-95* & 35.6 & $385 \rightarrow 306$ & - & - & - & 1.12 & 3.73 & 7.2 \\
\hline E1-4'-95 & 50.5 & $385 \rightarrow 306$ & $385 \rightarrow 278$ & 62.5 & 20 & 0.03 & 0.07 & 6.3 \\
\hline E2-4'-95 & 60.5 & $385 \rightarrow 306$ & $385 \rightarrow 278$ & 62.5 & 20 & 0.03 & 0.07 & 3.0 \\
\hline $3^{\prime}-101^{*}$ & 50.0 & $385 \rightarrow 306$ & - & - & - & 1.00 & 3.30 & 2.2 \\
\hline $4^{\prime}-101$ & 85.8 & $385 \rightarrow 278$ & $385 \rightarrow 306$ & 47.6 & 25 & 0.03 & 0.10 & 1.0 \\
\hline $5-110$ & 16.3 & $385 \rightarrow 306$ & - & - & - & 0.05 & 0.18 & 6.3 \\
\hline E1-5'-132 & 35.5 & $419 \rightarrow 340$ & - & - & - & - & - & - \\
\hline E2-5'-132 & 41.5 & $419 \rightarrow 340$ & - & - & - & - & - & - \\
\hline E1-4'-132 & 39.5 & $419 \rightarrow 312$ & $419 \rightarrow 340$ & 27.8 & 25 & 0.04 & 0.12 & 4.4 \\
\hline E2-4'-132 & 40.2 & $419 \rightarrow 312$ & $419 \rightarrow 340$ & 26.3 & 25 & 0.04 & 0.12 & 2.0 \\
\hline $3^{\prime}-141^{*}$ & 15.2 & $419 \rightarrow 340$ & $419 \rightarrow 312$ & 23.8 & 25 & 0.42 & 1.38 & 2.9 \\
\hline $4^{\prime}-141$ & 19.0 & $419 \rightarrow 312$ & $419 \rightarrow 340$ & 27.8 & 25 & 0.04 & 0.12 & 1.5 \\
\hline E1-5-149 & 31.8 & $419 \rightarrow 340$ & - & - & - & - & - & - \\
\hline E2-5-149 & 33.3 & $419 \rightarrow 340$ & - & - & - & - & - & - \\
\hline E1-4-149 & 37.9 & $419 \rightarrow 312$ & $419 \rightarrow 340$ & 31.3 & 25 & 0.04 & 0.15 & 2.3 \\
\hline E2-4-149 & 45.7 & $419 \rightarrow 312$ & $419 \rightarrow 340$ & 29.4 & 25 & 0.04 & 0.13 & 1.5 \\
\hline E1-5'-174 & 31.3 & $453 \rightarrow 374$ & - & - & - & - & - & - \\
\hline E2-5'-174 & 32.5 & $453 \rightarrow 374$ & - & - & - & - & - & - \\
\hline E1-4'-174 & 40.7 & $453 \rightarrow 346$ & $453 \rightarrow 374$ & 66.7 & 20 & 0.02 & 0.08 & 5.6 \\
\hline E2-4'-174 & 56.8 & $453 \rightarrow 346$ & $453 \rightarrow 374$ & 71.4 & 20 & 0.02 & 0.07 & 3.7 \\
\hline IS & 20.4 & $399 \rightarrow 320$ & - & - & - & 0.04 & 0.12 & - \\
\hline
\end{tabular}

a non-enantioselective column separating analytes from each other, and chiral analytes passed on to the second-dimension enantioselective column. Column-switching in this manner can reduce sample interferences with enantioselective separation [44], and was necessary given limitations in separations observed for enantioselective columns as noted below (Section 3.3.1).

\subsubsection{Enantioselective separation}

Normal phase provided the best separations for the purpose of stereoisomer quantification. While our separations under reversed-phase conditions were consistent with previous studies [21], as detailed in Supplemental Information, we were unable to avoid a number of co-elutions between congeners of the same mass. This problem rendered such separations unsuitable for quantitative purposes, because there would be no way to distinguish co-eluting isobaric congeners by MS.

Polysaccharide columns are extremely diverse in the types of chiral compounds that can be separated [45]. Indeed, we observed baseline separation on Chiralpak AD of $4^{\prime}-\mathrm{MeSO}_{2}-\mathrm{CB} 95,5^{\prime}-\mathrm{MeSO}_{2}-$ $\mathrm{CB} 174$, and $4^{\prime}-\mathrm{MeSO}_{2}-\mathrm{CB} 174$ with isocratic hexanes:isopropanol under $3-15 \%$ isopropanol and from 5 to $25^{\circ} \mathrm{C}$. Higher temperatures $\left(15-25^{\circ} \mathrm{C}\right)$ favored the separation of $4-\mathrm{MeSO}_{2}-\mathrm{CB} 91$ and $5^{\prime}-\mathrm{MeSO}_{2}$ $\mathrm{CB} 132$, while lower temperatures $\left(\leq 10^{\circ} \mathrm{C}\right)$ favored separation of 3'- $\mathrm{MeSO}_{2}-\mathrm{CB} 95,4^{\prime}-\mathrm{MeSO}_{2}-\mathrm{CB} 132$, and 5-MeSO $2-\mathrm{CB} 149$. Higher hexane composition (95-99\%) favored separation of $4-\mathrm{MeSO}_{2}$ CB91, 5'- $\mathrm{MeSO}_{2}-\mathrm{CB} 132,4^{\prime}-\mathrm{MeSO}_{2}-\mathrm{CB} 132$, and 5- $\mathrm{MeSO}_{2}-\mathrm{CB} 149$, whereas a lower proportion of nonpolar composition (85-90\%) was preferable for $3^{\prime}-\mathrm{MeSO}_{2}-\mathrm{CB} 95$. However, co-elution of $5^{\prime}-\mathrm{MeSO}_{2}$ $\mathrm{CB} 132$ and $4-\mathrm{MeSO}_{2}-\mathrm{CB} 149$ stereoisomers remained a problem. In addition, while the number of stereoisomer separations increased from that of other enantioselective columns tested, it was not possible to separate more than seven congeners simultaneously under a single isocratic run without a different polar modifier.

Near-baseline resolution of all chiral methylsulfonyl PCBs, except for $4^{\prime}-\mathrm{MeSO}_{2}-\mathrm{CB} 132\left(R_{S} \sim 0.8\right)$, was observed using 95:5 hexanes:ethanol at $20^{\circ} \mathrm{C}$. No single previously published method has achieved enantioseparation of more than 8 of the 10 chiral congeners. Indeed, apparent separation of two chiral but environmentally unstable congeners was observed under various normal phase eluent conditions (Figure S2). However, co-elutions of homologous $\mathrm{MeSO}_{2}$-CBs remained a problem. Methanol proved unsuitable, given solubility issues in hexanes $(<5 \%)$ and long equilibration times ( $>1 \mathrm{~h}$ at $1.0 \mathrm{~mL} / \mathrm{min}$ ) especially at decreased temperatures. Extremely broad peaks and irreproducible retention times were observed. These problems are consistent with incorporation of the polar modifier with the chiral stationary phase, which reaches a threshold level at ca. 5\%. Below this quantity, irreproducible separations can occur given slow mass transfer of the polar modifier between the mobile and stationary phases [45]. However, 8 of 10 chiral congeners were separated to baseline, and 4- $\mathrm{MeSO}_{2}-\mathrm{CB} 149$ partially separated $\left(R_{S} \sim 0.8\right)$ at $10^{\circ} \mathrm{C}$ with $90: 5: 5$ hexanes:methanol:ethanol. Addition of methanol to ethanol is suggested for improvement of enantiomer separations on polysaccharide stationary phases [45]. The number of co-elutions between congeners of the same mass was reduced, but not eliminated.

A subtle change in selectivity was observed when heptanes was used instead of hexanes. The use of heptanes in the final eluent composition allowed separation of E2-3'- $\mathrm{MeSO}_{2}-\mathrm{CB} 95$ from E1-4$\mathrm{MeSO}_{2}-\mathrm{CB} 91$, which was not achieved with any other mobile phase composition. Naturally, changes in elution order did occur upon 
switching mobile phases, possibly due to changes in the threedimensional structure of the polymeric carbohydrate stationary phase with changes in solvent [45]. Separations on Chiralpak AD-H, which was used for later methods development and for quantitation, were consistent with that for Chiralpak AD, but with reduced peak widths due to the decrease in particle size. Optimal enantiomer separations on Chiralpak AD-H were at either 90:5:5 heptanes:methanol:ethanol and $15^{\circ} \mathrm{C}$, or 95:2.5:2.5 heptanes:methanol:ethanol and $10^{\circ} \mathrm{C}$. However, co-elutions of isobaric congeners could not be avoided: $5-\mathrm{MeSO}_{2}-\mathrm{CB} 132$ co-eluted with 5 - $\mathrm{MeSO}_{2}-\mathrm{CB}$ 149. In addition, achiral congeners, which would be present in real environmental samples, also caused co-elutions, e.g., 3- $\mathrm{MeSO}_{2}-\mathrm{CB} 101,5-\mathrm{MeSO}_{2}-\mathrm{CB} 110$, and 4- $\mathrm{MeSO}_{2}-\mathrm{CB} 110$ all coeluted with $5-\mathrm{MeSO}_{2}-\mathrm{CB} 91$ stereoisomers. Finally, the internal standard's methyl group dissociated to some extent, resulting in potential interferences with co-eluting pentachloro- $\mathrm{MeSO}_{2}-\mathrm{CBs}$. Fortunately, it was completely resolved from all of these analytes under the optimal conditions stated above.

In summary, while the stereoisomers of all but one of the ten stable chiral environmentally relevant $\mathrm{MeSO}_{2}-\mathrm{CB}$ congeners are separable by normal phase enantioselective chromatography, this separation is insufficient for trace environmental analysis unless interfering congeners can be isolated, and preferably also quantified. Liquid chromatography with more than one column is required, which in turn requires an appropriate nonenantioselective separation.

\subsection{2. $\mathrm{MeSO}_{2}-\mathrm{CB}$ separation by ortho-chlorination}

While it is possible to adjust and optimize separations on the columns of a multi-column liquid chromatography system independently, this requires more than one pump, which we lacked, as well as additional complexity, which we wished to avoid. Thus, the optimal eluent conditions for stereoisomer separations (Section 3.3.1) were used for separating $\mathrm{MeSO}_{2}$ congeners (Figure S3).

Separation for PCB fractionation on the PYE stationary phase is based primarily on $\pi-\pi$ interactions [46], and is consistent with our observations for $\mathrm{MeSO}_{2}$-CBs. As ortho-chlorination increases, the angle of declination between the two phenyl rings increases, and interaction with the stationary phase decreases. Retention for a given number of ortho- $\mathrm{Cl}$ also increases with increasing chlorination, due to electrostatic interactions between the high electron affinity $\mathrm{Cl}$ atoms and the electron-donating pyrene moiety of the stationary phase. The PYE column provided sufficient $\mathrm{MeSO}_{2}-\mathrm{CB}$ separation so as to be useful for our purposes, with structureretention relationships consistent with that previously observed for parent PCBs [46] (Supplemental Information).

\subsubsection{Column-switching liquid chromatography}

Once the PYE and Chiralpak AD-H columns were connected in series, some small adjustments were made in the two sets of optimal enantioselective chromatographic conditions (Section 3.3.1) to achieve the final method (Section 2.2). There were some trade-offs in resolution between the $10^{\circ} \mathrm{C}$ and $15^{\circ} \mathrm{C}$ methods, with better resolution between $\mathrm{E} 1-4-\mathrm{MeSO}_{2}-\mathrm{CB} 95$ and $3-\mathrm{MeSO}_{2}-\mathrm{CB} 91$ at $10^{\circ} \mathrm{C}$ but worse resolution between $\mathrm{E} 1$ and $\mathrm{E} 2-4-\mathrm{MeSO}_{2}-132$ at $15^{\circ} \mathrm{C}$ and vice versa. A temperature of $12.5^{\circ} \mathrm{C}$ provided a nice balance and gave acceptable resolution in both cases (Fig. 2). For future analyses, a temperature of $15^{\circ} \mathrm{C}$ is recommended to improve the resolution of 4- $\mathrm{MeSO}_{2}-\mathrm{CB} 132$, since this congener is generally detected much more frequently in the environment than $5-\mathrm{MeSO}_{2}-\mathrm{CB} 91$ or 4- $\mathrm{MeSO}_{2}$-CB95 [1].

During column-switching, there was no solvent flow through the enantioselective column when achiral analytes were directed from the PYE column to the detector. There was no noticeable increase in peak width between analytes held on the enantioselective column were compared to those from a chromatogram where the analytes were passed directly through both columns with no stop in flow. This observation is consistent with the low amount of longitudinal diffusion expected under stopped flow conditions at a temperature below ambient. The molecular diffusivity of penta$\mathrm{MeSO}_{2}-\mathrm{CB}$ was estimated using Wilke-Chang theory [47] to be $4.6 \times 10^{-5} \mathrm{~cm}^{2} / \mathrm{s}$, based on an estimated solute molal volume of $180 \mathrm{~cm}^{2} / \mathrm{g} \mathrm{mol}$ of the structurally similar bromonapthalene and a viscosity of $0.409 \mathrm{cP}$ for heptane at $12.5^{\circ} \mathrm{C}$. The low temperature and a mobile phase composition high in heptane, with a low solvent association parameter of unity [47], helped to keep molecular diffusion to a minimum during stopped flow. Over the stopped flow time of $9.2 \mathrm{~min}$, a peak should diffuse $0.2 \mathrm{~cm}$, which corresponds to a diffusion plug volume of $0.037 \mathrm{~cm}^{3}$ for a $4.6 \mathrm{~mm}$ i.d. column. The resulting increase in width of the analyte plug from molecular diffusion during stopped flow is roughly $3.7 \%$, which is negligible. This calculation is an oversimplification, because the effects of additional mobile phase components and the chemical interactions of the solute with the stationary phase are ignored, and also because tortuosity was ignored. The latter would decrease the extent of molecular diffusion, making the above calculation an over-estimation.

In the final method (Fig. 2), all chiral congeners were separated without interferences from achiral congeners. The only instances where baseline resolution was not achieved was between E1 and E2-4- $\mathrm{MeSO}_{2}-\mathrm{CB} 132$, and between E1-4- $\mathrm{MeSO}_{2}-\mathrm{CB} 95$ and E1 + E2$5-\mathrm{MeSO}_{2}$-CB91. However, in the latter case, the $385.0 \rightarrow 278.0$ transition was quite high for 4- $\mathrm{MeSO}_{2}-\mathrm{CB} 95$ and quite low (barely visible, Fig. 2) for 5-MeSO ${ }_{2}-\mathrm{CB} 91$, so in instances where both compounds were detected, this transition could be used to allow for better quantification of $4-\mathrm{MeSO}_{2}-\mathrm{CB95}$. This was not necessary in this study since neither compound was detected in any of the samples tested (Section 3.6). The internal standard was fully resolved from all penta-chlorinated congeners, and many of the achiral congeners were resolved, making this a comprehensive method for $\mathrm{MeSO}_{2}-\mathrm{CB}$ analysis. Co-elution with parent PCBs, while possible if both are co-injected, is not a problem on a practical basis, given that parent PCBs and $\mathrm{MeSO}_{2}-\mathrm{CBs}$ are separated during column cleanup and fractionation (Supplemental Information). Such processing must be done to reduce co-extracted matrix material to a manageable level. The total run time was $93 \mathrm{~min}$, a reduction of approximately one-third compared to the fastest GC-based method reported [10], and more than three times compared to the slowest published enantioselective GC methods [48].

\subsection{Method performance}

Analytes were not present in blanks. The limits of detection (LOD) and limits of quantitation (LOQ, Table 3) were assessed as the average noise of blanks, plus three and ten times the standard deviation of the noise, respectively. Values for LOQ ranged from $0.02 \mathrm{ng}$ on-column for E2-4'-95 to $5.8 \mathrm{ng}$ on-column for 3'-49, with meta$\mathrm{MeSO}_{2}-\mathrm{CBs}$ having considerably worse detection limits for reasons previously noted except for 3- $\mathrm{MeSO}_{2}-\mathrm{CB} 70, \mathrm{E} 1+\mathrm{E} 2-5-\mathrm{MeSO}_{2}$ $\mathrm{CB} 91$, and $5-\mathrm{MeO}_{2}-\mathrm{CB} 110$. Three meta-substituted congeners could not be detected in this analysis and were excluded from further

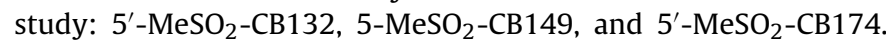
Attempts to improve sensitivity for other meta- $\mathrm{MeSO}_{2}-\mathrm{CBs}$ were not successful, including use of Ar collision gas, enhanced product ion scanning on the linear ion trap of the QTrap mass spectrometer, and use of different dopants. Reduced sensitivity for meta- $\mathrm{MeSO}_{2}$ CBs has also been encountered in previously published GC-MS methods [38].

While it is clear that analysis of most meta- $\mathrm{MeSO}_{2}-\mathrm{CBs}$ is difficult using our method, our detection and quantification limits for other analytes are comparable to GC-based methods. Detection limits for enantioselective GC-ion trap MS were reported at $10-50 \mathrm{pg}$ per 

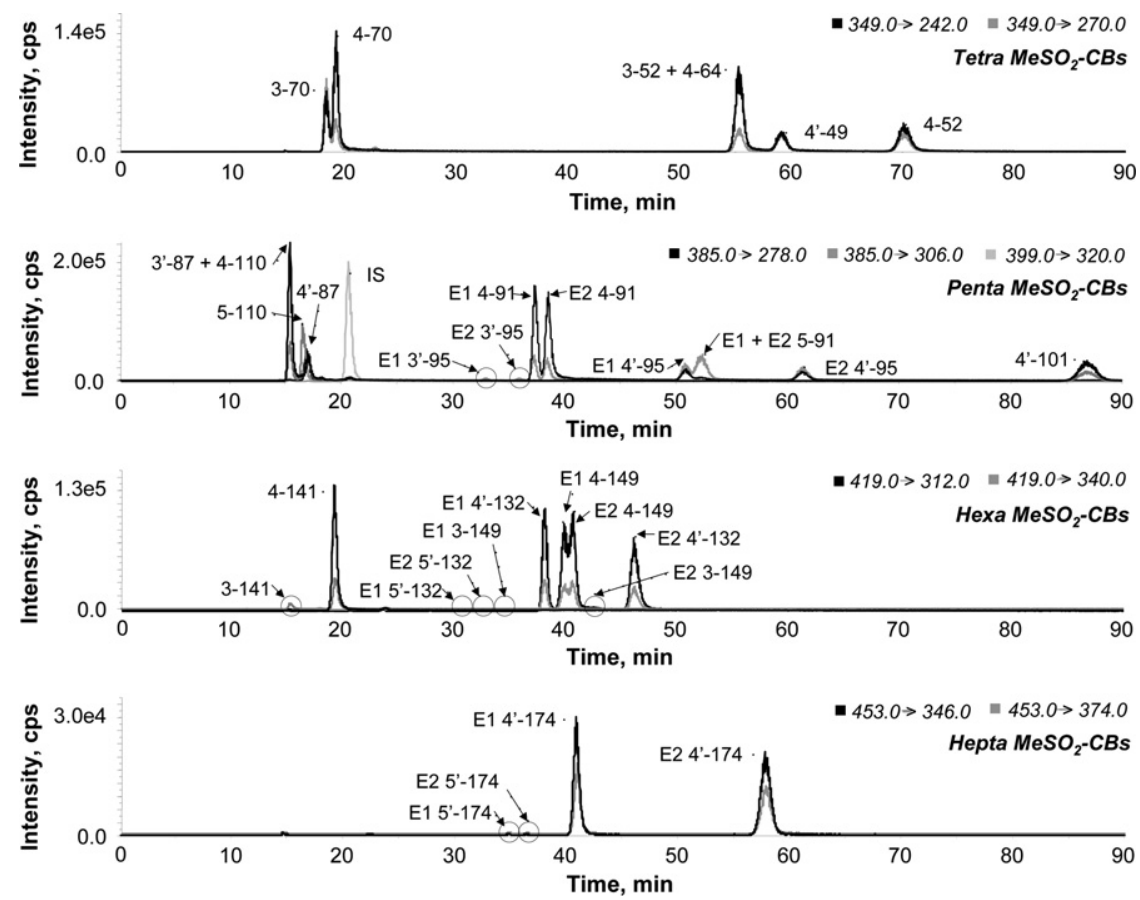

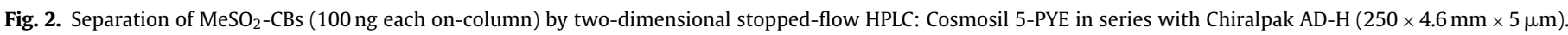

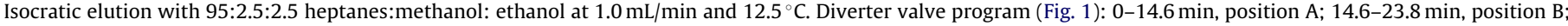
23.8-91 min, position A. Low intensity peaks are circled. Internal standard (IS): 3-MeSO $2-4-\mathrm{Me}_{2} 2^{\prime} 3^{\prime} 4^{\prime}, 5,5^{\prime}$-pentachlorobiphenyl.

enantiomer, similar to our observations (Table 3). It should be noted that GC-ECNI-MS, the typical method used for $\mathrm{MeSO}_{2}-\mathrm{CB}$ quantitation, has detection limits in the single-digit pg on-column range $[49,50]$. This is better than our reported sensitivity, and is a reason why studies measuring $\mathrm{MeSO}_{2}-\mathrm{CB}$ atropisomers will first quantify using non-enantioselective chromatography $[11,48]$ before measuring enantiomer composition. Indeed, most studies of chiral chemicals in general [51] will not quantify using enantioselective columns, as these tend to be less efficient than non-enantioselective columns. However, such measurements require two separate analyses, with the enantioselective GC method taking much longer than our method, which can simultaneously measure both achiral and chiral $\mathrm{MeSO}_{2}-\mathrm{CBs}$ without losses in chromatographic efficiency.

For all analytes, a high level of linearity was observed for standard concentrations from 0.1 to $100 \mathrm{ng}$ on-column, with the majority of the linear regression correlation coefficients $\left(r^{2}\right)$ falling between 0.9906 to 0.9999 . The lowest correlations were for 3- $\mathrm{MeSO}_{2}-\mathrm{CB} 141$ and the peak corresponding to 3- $\mathrm{MeSO}_{2}-\mathrm{CB} 87+4-$ $\mathrm{MeSO}_{2}-\mathrm{CB} 110$, at 0.9669 and 0.9762 , respectively. If the highest calibration point ( $5000 \mathrm{ng} / \mathrm{mL}$ or $100 \mathrm{pg}$ on-column) was excluded, the correlation coefficients increased to 0.9921 and 0.9999 , respectively, suggesting that the linearity range for these compounds may be between $20 \mathrm{ng}$ (the next highest calibration concentration) and $50 \mathrm{ng}$. Our observed linearity is comparable to that of GC-ECD methods, which typically obtain $2-3$ orders of magnitude [49].

Precision was assessed by analyzing a $100 \mathrm{ng} / \mathrm{mL}$ mixed standard solution three times consecutively for most congeners. A $5000 \mathrm{ng} / \mathrm{mL}$ solution was used for 3- $\mathrm{MeSO}_{2} 2-\mathrm{CB} 49,3-\mathrm{MeSO}_{2}-\mathrm{CB} 95$, $3-\mathrm{MeSO}_{2}-\mathrm{CB} 101$, and 3- $\mathrm{MeSO}_{2}-\mathrm{CB} 141$, given the poor sensitivity for these meta congeners. The percent relative standard deviation (\% RSD) for each analyte was less than 11\% (Table 3). The major expection was for $3-\mathrm{MeSO}_{2}-\mathrm{CB} 49$ at $38.1 \%$, attributable to this congener being just above its LOD, and therefore difficult to measure. Our observed precision is within the range $(<12 \% \mathrm{RSD})$ of that observed for GC-based analysis methods for $\mathrm{MeSO}_{2}-\mathrm{CBs}$, both for non-enantioselective GC-ECD [49] and GC-NICI-MS [13], as well as enantioselective multidimensional GC-ECD [20].

The EF precision for chiral congeners in the above analysis had a $\%$ RSD less than $3 \%$ in all cases. The EFs for racemic 4- $\mathrm{MeSO}_{2}-\mathrm{CB} 95$ and 4- $\mathrm{MeSO}_{2}-\mathrm{CB} 174$ had the highest deviations from the theoretical value of 0.5 . This is likely attributable to the large enantiomer separation achieved for these congeners, with approximately 10 and $18 \mathrm{~min}$, respectively, between peaks. Because isocratic elution was used, the E2-enantiomer peak was significantly broader and shorter than the E1 peak. This results in a decrease in detectability and therefore peak area in the former relative to E1, and a consequent increase in EF. There are methods of correcting for standard EFs that are different from 0.5 [52]. However, this was not deemed necessary in the current work since the EFs were expected to be either very near or very different from 0.5 due to the high level of enantioselectivity typically observed for many $\mathrm{MeSO}_{2}-\mathrm{CBs}$ as noted below. Other stereoisomers were not quantified given lack of enantiomer separation or poor sensitivity as discussed.

Accuracy was assessed by extracting and analyzing US National Institute of Standards and Technology Standard Reference Material (SRM) 1945 Organics in Whale Blubber (Gaithersburg, MD, USA) and comparing concentrations of individual congeners to those determined by GC-ECD in a previous study [50]. While neither this SRM nor any other to our knowledge is certified for $\mathrm{MeSO}_{2}$ CBs, it remains useful as a relevant environmental matrix with a known and consistent level of these contaminants of interest $[50,53]$. Due to differences in the target analytes selected and in co-elutions of congeners between the two methods, only three congeners could be directly compared: 4- $\mathrm{MeSO}_{2}-\mathrm{CB} 64,3-\mathrm{MeSO}_{2}$ $\mathrm{CB} 70$, and $4-\mathrm{MeSO}_{2}-\mathrm{CB} 70$ we found at $0.53,0.54$, and $0.61 \mathrm{ng} / \mathrm{g}$ lipid weight. These were previously measured by GC-based methods at $0.56 \pm 0.04,0.58 \pm 0.02$, and $0.84 \pm 0.06 \mathrm{ng} / \mathrm{g}$ lipid weight, respectively [50], for a difference of $4.9 \%, 6.4 \%$, and $27.7 \%$, respectively. The apparently large difference for $4-\mathrm{MeSO}_{2}-\mathrm{CB} 70$ is reasonable considering reported errors in the respective measurements of $22.8 \%$ for the current analysis, from propagated error of multiple standard 
measurements and spiking volume, and 7.1\% for Hoekstra et al. [50]. These results suggest that the accuracy of our method is suitable for quantitative trace environmental analysis of $\mathrm{MeSO}_{2}$-CBs.

\subsection{Matrix effects}

Extracted SRM 1945 was analyzed in two different ways to identify potential matrix effects. First, the matrix was extracted [54] in a manner similar to that for sledge dog samples, but the chlorinated pesticide fraction was collected instead. This fraction was selected because it was polar enough to collect matrix components similar to that in a $\mathrm{MeSO}_{2}-\mathrm{CB}$ fraction, but not so polar as to elute any interfering $\mathrm{MeSO}_{2}$-CBs. Analyses of a $100 \mathrm{ng} / \mathrm{mL} \mathrm{MeSO}_{2}$ $\mathrm{CB}$ mixed standard, a blank extracted matrix, and a matrix spiked at $100 \mathrm{ng} / \mathrm{mL}$ for each $\mathrm{MeSO}_{2}-\mathrm{CB}$ were performed in triplicate each. Four congeners were excluded from this analysis: $3^{\prime}-\mathrm{MeSO}_{2}-49$, $3^{\prime}-\mathrm{MeSO}_{2}-\mathrm{CB} 95$, and $3^{\prime}-\mathrm{MeSO}_{2}-\mathrm{CB} 141$ were not detectable in this analysis, while the peak for $4-\mathrm{MeSO}_{2}-\mathrm{CB} 101$ was truncated in some runs given slight increases in retention time during the course of sample analysis (see below).

No $\mathrm{MeSO}_{2}$-CBs were detected in the blank extracted matrix. Significant differences were found between the two analytebearing groups for 4- $\mathrm{MeSO}_{2}-\mathrm{CB} 52,4-\mathrm{MeSO}_{2}-\mathrm{CB} 64,3-\mathrm{MeSO}_{2}-$ $\mathrm{CB} 87+4-\mathrm{MeSO}_{2}-\mathrm{CB} 110,5-\mathrm{MeSO}_{2}-\mathrm{CB} 110, \mathrm{E} 2-4-\mathrm{MeSO}_{2}-\mathrm{CB} 132$, and $4-\mathrm{MeSO}_{2}-\mathrm{CB} 141$. However, the \% RSD was $15.2 \%$ for $5-\mathrm{MeSO}_{2}$ CB110 and less than 9.3\% for the remaining analytes. These values are on par with those for the precision experiments (11\%), so the variation observed here could be attributable to change in instrumental response.

The \% RSD of EFs between the standard solutions and the spiked matrix samples was less than $3 \%$ for all chiral congeners except $4^{\prime}-\mathrm{MeSO}_{2}-\mathrm{CB} 132$ at $6.7 \%$. This observation is on par with the $3 \%$ RSD observed in EF precision experiments (11\%), again suggesting that the observed variation with matrix was due to instrumental responses. The larger \% RSD for $4^{\prime}-\mathrm{MeSO}_{2}-\mathrm{CB} 132$ was biased because of a single run that could be considered an outlier; if this data point is excluded, the variation decreased to $3.7 \%$.

The lack of significant matrix effects observed in this study is consistent with the low amount of ion signal modification characteristic of the ionization process in APPI [23]. Significantly reduced matrix effects were obtained using APPI instead of electrospray ionization for LC-MS analysis of perfluorinated compounds [55]. Likewise, hexabromocyclododecane enantiomers in environmental matrices demonstrated lower signal modification and fewer non-racemic measurement artifacts with APPI compared to ESI [24]. Our results suggest that APPI-based analysis is viable for environmental analysis of $\mathrm{MeSO}_{2}-\mathrm{CBs}$.

While no significant matrix effects were found, we did observe a small increase (ca. $2 \mathrm{~min}$ ) in retention time for all analytes over the course of the sample analyses (Section 3.6). This is possibly from buildup of lipids and other biogenic material, consistent with the PYE stationary phase being notoriously sensitive to lipids [56]. Regular changes of the PYE guard column is recommended, as well as appropriate lipid cleanup procedures.

\subsection{Analysis of methylsulfonyl PCBs in sledge dog tissues}

The majority of achiral congeners were detected in at least one of the 27 sledge dog samples with quantifiable $\mathrm{MeSO}_{2}-\mathrm{CBs}$ in the current study, except $3^{\prime}-\mathrm{MeSO}_{2}-\mathrm{CB} 101$ and $4^{\prime}-\mathrm{MeSO}_{2}-\mathrm{CB} 141$ which were not observed. Of the chiral congeners, only 4- $\mathrm{MeSO}_{2}$ CB91, 4'- $\mathrm{MeSO}_{2}-\mathrm{CB} 132$, 4- $\mathrm{MeSO}_{2}-\mathrm{CB} 149$, and 5- $\mathrm{MeSO}_{2}-\mathrm{CB} 149$ were detected, albeit below the LOQ for the last congener. These chiral congeners have also been commonly found in mammals in previous work [11-13,48]. Congener patterns were quite similar among the various sample groups; however, 4- $\mathrm{MeSO}_{2}-\mathrm{CB} 91$

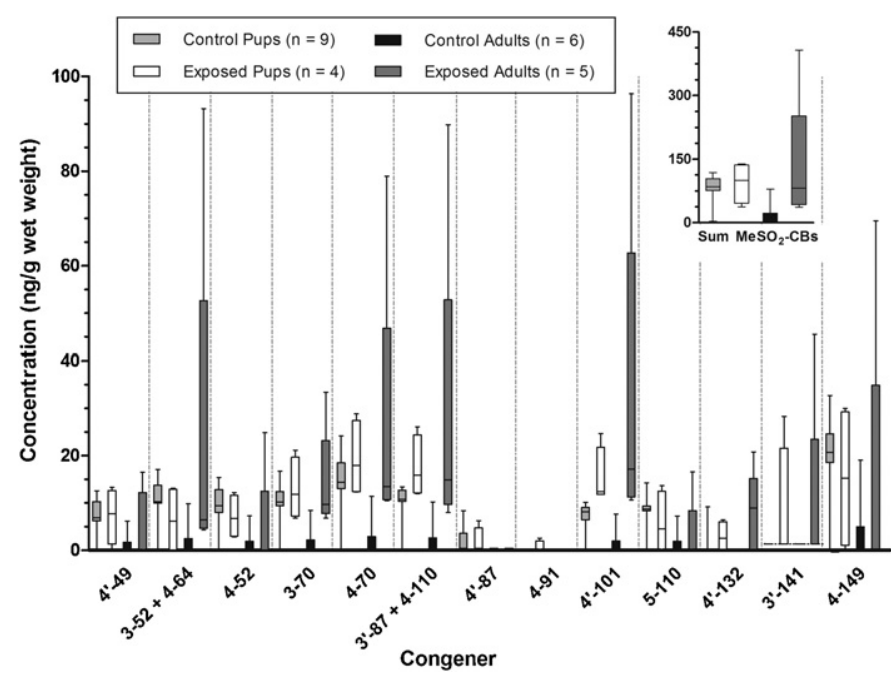

Fig. 3. Distribution of $\mathrm{MeSO}_{2}-\mathrm{CB}$ concentrations ( $\mathrm{ng} / \mathrm{g}$ wet weight) in Greenland sledge dog adipose tissues. Censored box plots: top and bottom of boxes are 25th and 75th percentiles, respectively; center line is median value, top and bottom of whiskers are minimum and maximum. Horizontal dotted lines are LOQs for each congener, which may not be visible at this scale. Median for control adults at LOQ for all congeners and $\Sigma$-MeSO $\mathrm{O}_{2}$-CBs. Sum concentration (ng/g wet weight) of chiral congeners 4- $\mathrm{MeSO}_{2}-\mathrm{CB} 91,4^{\prime}-\mathrm{MeSO}_{2}-\mathrm{CB} 132$, and 4- $\mathrm{MeSO}_{2} 2-\mathrm{CB} 149$ in inset.

and $3^{\prime}-\mathrm{MeSO}_{2}-\mathrm{CB} 141$ were found only in exposed dogs, while $4^{\prime}-\mathrm{MeSO}_{2}-\mathrm{CB} 142$ was observed in all sample groups but the control adults. Differences in congener profiles between control and exposed dogs may simply be a function of concentration differences. Alternatively, they may result from induction of cytochrome $\mathrm{P}-450$ isozymes initiating the biotransformation of parent PCBs to $\mathrm{MeSO}_{2}-\mathrm{CBs}$, consistent with observed differences in parent PCBs among the various groups [30], and with higher measured 7-ethoxyresorufin $O$-dealkylase and epoxide hydroxylase activities in exposed versus control dogs [29].

The highest $\mathrm{MeSO}_{2}-\mathrm{CB}$ concentrations and greatest variation between individuals in a group were observed in exposed adults (Fig. 3). There was a higher concentration of total $\mathrm{MeSO}_{2}-\mathrm{CBs}$ in exposed adults compared to control adults, and in exposed pups compared to control pups, although in neither case were these differences significant. As with parent total PCBs, no differences in total $\mathrm{MeSO}_{2}$-CBs were observed between exposed adults and pups, consistent with the idea that concentrations of these contaminants may reach an equilibrium state early in life [28].

Enantiomer fraction (Fig. 4) data is limited, because EFs were only calculated when at least one of the enantiomers were above the LOQ. If only one enantiomer was found at a concentration exceeding the LOQ then the LOQ concentration was used for the other enantiomer to calculate a floor/ceiling value for the EF. This was the case for all samples for $4^{\prime}-\mathrm{MeSO}_{2}-\mathrm{CB} 132$, for one of the sledge dog samples for $4-\mathrm{MeSO}_{2}-\mathrm{CB} 149$, and for the single sample in which 4- $\mathrm{MeSO}_{2}-\mathrm{CB} 91$ was measurable (Fig. 4). For 4-MeSO CB149, most dogs had a slight enrichment of the E2-enantiomer, but not significantly so for all dog EFs together compared to racemic standards. Highly enantioselective $\mathrm{MeSO}_{2}-\mathrm{CB}$ residues, up to the point of only detecting one enantiomer (i.e., EFs near zero or unity) have been observed in adipose tissues of a number of mammals, including polar bears (Ursus maritimus) [11], pinnipeds [11-13] including ringed seals (Pusa hispida) [11] and grey seals (Haliocherus grypus) [12], harbor porpoises (Phocoena phocoena) [48], and rats fed PCBs in in vivo biotransformation experiments $[14,15]$. Because enantiomer elution order is unknown and may differ for various stationary phases and methods, it is impossible to compare our EF results directly with those of others. However, it is clear that formation of $\mathrm{MeSO}_{2}$-CBs in mammals can be a highly 
4-91

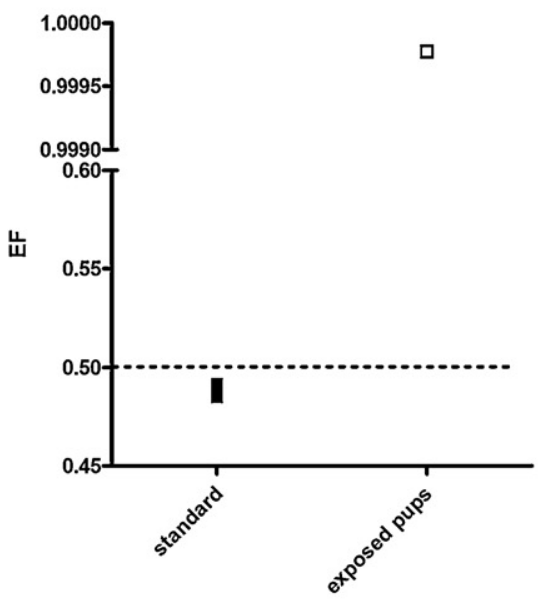

4-132

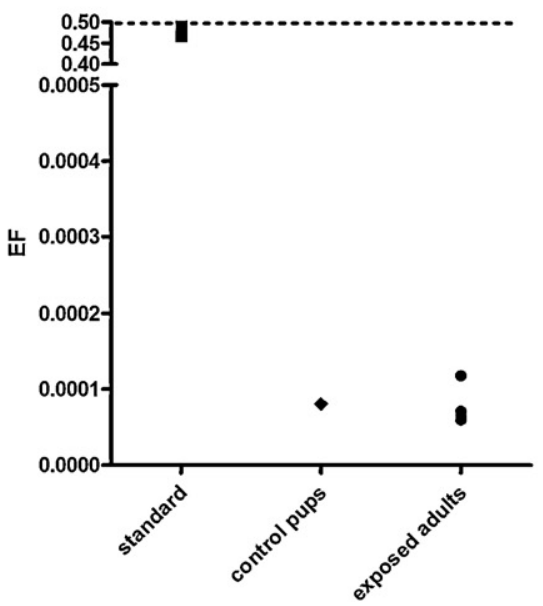

4-149

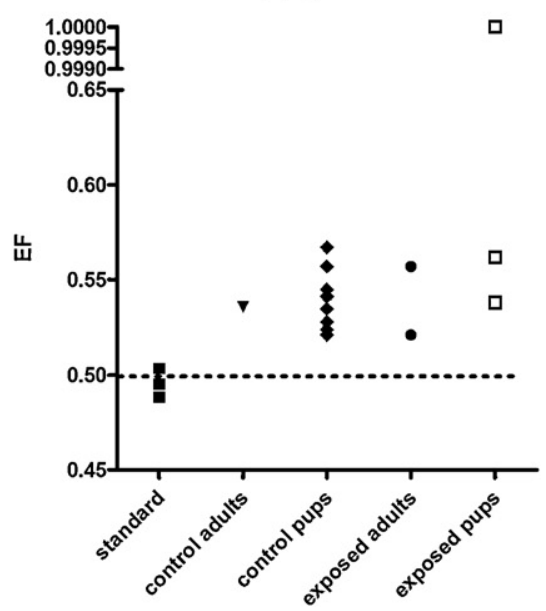

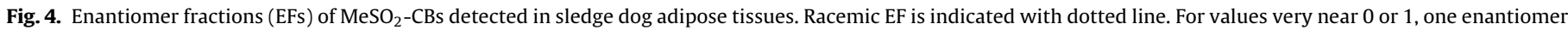
was not detected, and its concentration was taken to be the limit of quantification for EF calculation purposes.

stereoselective process. The $\mathrm{MeSO}_{2}-\mathrm{CB}$ enantiomer composition in sledge dogs may be due to enantioselective biotransformation, although we cannot rule out the possibility of dietary sources.

\section{Conclusions}

The enantiomers of nine of the ten environmentally relevant chiral PCB methyl sulfones were separated by column-switching LC-MS-MS. More congeners can be separated by normal phase enantioselective LC compared to any previous enantioselective GC method. The current technique also improves over previous enantioselective GC methods in terms of analysis time by up to a factor of three. Use of an non-enantioselective first-dimension separation enabled quantification of many achiral congeners that otherwise interfered with enantioselective analysis. Atmospheric pressure photoionization, which has not been previously applied to PCB metabolite analysis, was successfully employed for quantification of several para- and meta-substituted congeners in West Greenland sledge dog adipose tissue extracts. However, eight of the meta- $\mathrm{MeSO}_{2}-\mathrm{CBs}$ of environmental interest could not be quantified due to poor response, although similar difficulties have been noted with the use of GC-MS. Nonetheless, this study establishes that APPI, combined with column-switching LC-MS-MS, is a viable means by which to perform trace analysis of these contaminants in complex matrices. Performance for meta-MeSO $\mathrm{S}_{2}$-CBs may potentially be improved through selection of alternate parameters, such as changing column temperature to increase $4^{\prime}-\mathrm{MeSO}_{2}-\mathrm{CB} 132$ resolution, increasing dwell time to improve overall signal-to-noise ratios, or using mixed dopants [57].

\section{Acknowledgements}

We thank Thomas Dau Rasmussen, Anne Silverbau, Mikael and Jane Rasmussen, Jørn Breinholt, and Jens Kjeldsen for their roles in handling the sledge dogs, Sohiela Shahmiri for sample extraction, and Kathy Yackulic for laboratory assistance. Funding was provided by the Danish Cooperation for Environment in the Arctic (DANCEA), the Lundbech Foundation, the Natural Sciences and Engineering Research Council of Canada, the Early Career Award for Applied Ecological Research co-sponsored by the Society of Environmental Toxicology and Chemistry and the American Chemistry Council, and the Canada Research Chairs program.

\section{Appendix A. Supplementary data}

Supplementary data associated with this article can be found, in the online version, at http://dx.doi.org/10.1016/j.chroma. 2012.10.030.

\section{References}

[1] R.J. Letcher, E. Klasson-Wehler, Å. Bergman, in: J. Paasivirta (Ed.), The Handbook of Environmental Chemistry, vol. 3K, Springer-Verlag, 2000, p. 315.

[2] Y. Kato, K. Haraguchi, K. Tomiyasu, H. Saito, M. Isogai, Y. Masuda, R. Kimura, Environ. Toxicol. Pharmacol. 3 (1997) 137.

[3] Y. Kato, K. Haraguchi, T. Shibahara, S. Yumoto, Y. Masuda, R. Kimura, Chemosphere 40 (2000) 1233.

[4] M. Heneweer, M. van den Berg, M.C. de Geest, P.C. de Jong, Å. Bergman, J.T. Sanderson, Toxicol. Appl. Pharmacol. 202 (2005) 50.

[5] R.J. Letcher, J.G. Lemmen, B. van der Berg, A. Brouwer, Å. Bergman, J.P. Giesy, M. van den Berg, Toxicol. Sci. 69 (2002) 362.

[6] B.-O. Lund, J. Örberg, Å. Bergman, C. Larsson, A. Bergman, B.-M. Bäcklin, H. Håkansson, A. Madej, A. Brouwer, B. Brunström, Environ. Toxicol. Chem. 18 (1999) 292.

[7] M. Johansson, S. Nilsson, B.-O. Lund, Environ. Health Perspect. 106 (1998) 769.

[8] H.-J. Lehmler, S.J. Harrad, H. Hühnerfuss, I. Kania-Korwel, C.M. Lee, Z. Lu, C.S. Wong, Environ. Sci. Technol. 44 (2010) 2757.

[9] T. Nezel, F. Müller-Plathe, M.D. Müller, H.-R. Buser, Chemosphere 35 (1997) 1895.

[10] T. Ellerichmann, Å. Bergman, S. Franke, H. Hühnerfuss, E. Jakobsson, W.A. König, C. Larsson, Fresenius Environ. Bull. 7 (1998) 244.

[11] K. Wiberg, R. Letcher, C. Sandau, J. Duffe, R. Norstrom, P. Haglund, T. Bidleman, Anal. Chem. 70 (1998) 3845.

[12] C. Larsson, K. Norström, I. Athanansiadis, A. Bignert, W.A. König, Å. Bergman, Environ. Sci. Technol. 38 (2004) 4950.

[13] L. Karásek, J. Hajšlová, J. Rosmus, H. Hühnerfuss, Chemosphere 67 (2007) S22.

[14] C. Larsson, T. Ellerichmann, H. Hühnerfuss, Å. Bergman, Environ. Sci. Technol. 36 (2002) 2833.

[15] K. Norström, J. Eriksson, J. Haglund, V. Silvari, Å. Bergman, Environ. Sci. Technol. 40 (2006) 7649.

[16] M. Püttmann, A. Mannschreck, F. Oesch, L. Robertson, Biochem. Pharmacol. 38 (1989) 1345.

[17] L.E. Rodman, S.I. Shedlofsky, A. Mannschreck, M. Püttmann, A.T. Swim, L.W. Robertson, Biochem. Pharmacol. 41 (1991) 915.

[18] I.N. Pessah, H.-J. Lehmler, L.W. Robertson, C.F. Perez, E. Cabrales, D.D. Bose, W. Fang, Chem. Res. Toxicol. 22 (2009) 201.

[19] H.-J. Lehmler, L.W. Robertson, A.W. Garrison, P.R.S. Kodavanti, Toxicol. Lett. 156 (2005) 391.

[20] V. Pérez-Fernández, M. Castro-Puyana, M.J. González, M.L. Marina, M. Ángeles García, B. Gómara, Chirality 24 (2012) 577.

[21] H. Pham-Tuan, C. Larsson, F. Hoffmann, Å. Bergman, M. Fröba, H. Hühnerfuss, Chirality 17 (2005) 266.

[22] P. Haglund, Chemosphere 32 (1996) 2133.

[23] S.J. Bos, S.M. van Leeuwen, U. Karst, Anal. Bioanal. Chem. 384 (2006) 85.

[24] M.S. Ross, C.S. Wong, J. Chromatogr. A 1217 (2010) 7855.

[25] J. Maervoet, A. Covaci, P. Schepens, C.D. Sandau, R.J. Letcher, Environ. Health Perspect. 112 (2004) 291. 
[26] L. Ramos, L.M. Hernández, M.J. González, Anal. Chem. 71 (1999) 70.

[27] J. Verreault, R.J. Letcher, C. Sonne, R. Dietz, Environ. Int. 35 (2009) 56.

[28] J. Verreault, R. Dietz, C. Sonne, W.A. Gebbink, S. Shahmiri, R.J. Letcher, Comp. Biochem. Physiol. C 147 (2008) 306.

[29] J. Verreault, F. Maisonneuve, R. Dietz, C. Sonne, R.J. Letcher, Environ. Toxicol. Chem. 28 (2009) 162.

[30] J. Verreault, R.J. Letcher, C. Sonne, R. Dietz, Comp. Biochem. Physiol.C 150(2009) 91.

[31] W.A. Gebbink, C. Sonne, R. Dietz, M. Kirkegaard, F.F. Riget, E.W. Born, D.C.G. Muir, R.J. Letcher, Environ. Pollut. 152 (2008) 621

[32] J. Verreault, R.J. Letcher, D.C.G. Muir, S. Chu, W.A. Gebbink, G.W. Gabrielsen, Environ. Toxicol. Chem. 24 (2005) 2486.

[33] B.J. Asher, L.A. D’Agostino, J.D. Way, C.S. Wong, J.J. Harynuk, Chemosphere 75 (2009) 1042.

[34] T. Harner, K. Wiberg, R. Norstrom, Environ. Sci. Technol. 34 (2000) 218.

[35] T.J. Kauppila, T. Kotiaho, R. Kostiainen, A.P. Bruins, J. Am. Soc. Mass Spectrom. 15 (2004) 203.

[36] D.I. Carroll, I. Dzidic, E.C. Horning, R.N. Stillwell, Appl. Spectrosc. Rev. 17 (1981) 337.

[37] K. Haraguchi, Å. Bergman, E. Jakobsson, Y. Masuda, Fresenius J. Anal. Chem. 347 (1993) 441.

[38] R.J. Letcher, R.J. Norstrom, J. Mass Spectrom. 32 (1997) 232.

[39] D.B. Robb, M.W. Blades, J. Am. Soc. Mass Spectrom. 16 (2005) 1275.

[40] J. Chen, W.A. Korfmacher, Y. Hsieh, Chromatogr. B 820 (2005) 1.

[41] T. Kauppila, A.P. Bruins, R. Kostiainen, J. Am. Soc. Mass Spectrom. 16 (2005) 1399.
[42] I. Dzidic, D.I. Carroll, R.N. Stillwell, E.C. Corning, Anal. Chem. 47 (1975) 1308

[43] European Commission, Off. J. Eur. Commun. L221 (2002) 8.

[44] K.R. Ing-Lorenzini, J.A. Desmeules, M. Besson, J.-L. Veuthey, P. Dayer, Y. Daali, J. Chromatogr. A 1216 (2009) 3851.

[45] R.W. Stringham, Advances in Chromatography, vol. 44, CRC Press, 2006, p. 257

[46] P. Haglund, L. Asplund, U. Järnberg, B. Jansson, J. Chromatogr. 507 (1990) 389.

[47] C.R. Wilke, P. Chang, AIChE J. 1 (1955) 264

[48] S. Chu, A. Covaci, K. Haraguchi, S. Voorspoels, K. Van de Vijver, K. Das, J.-M Bouquegneau, W. De Coen, R. Blust, P.Schepens, Environ. Sci. Technol. 37 (2003) 4573.

[49] R.J. Letcher, R.J. Norstrom, A. Bergman, Sci. Total Environ. 160/161 (1995) 409.

[50] P.F. Hoekstra, R.J. Letcher, T.M. O’Hara, S.M. Backus, K.R. Solomon, D.C.G. Muir Environ. Toxicol. Chem. 22 (2003) 2650.

[51] C.S. Wong, B.H. Elmayergi, in: E.A. Myers (Ed.), Encyclopedia of Analytical Chemistry, vol. S1-S3, Wiley, 2009, p. 220.

[52] S.L. MacLeod, P. Sudhir, C.S. Wong, J. Chromatogr. A 1170 (2007) 23.

[53] C.S. Wong, P.F. Hoekstra, H. Karlsson, S.M. Backus, S.A. Mabury, D.C.G. Muir, Chemosphere 49 (2002) 1339.

[54] J.A. Morrissey, D.S. Bleackley, N.A. Warner, C.S. Wong, Chemosphere 66 (2007) 326.

[55] S. Chu, R.J. Letcher, J. Chromatogr. A 1215 (2008) 92.

[56] M. Concejero, L. Ramos, B. Jiménez, B. Gómara, E. Abad, J. Rivera, M.J. González, J. Chromatogr. A 917 (2001) 227.

[57] N. Itoh, Y. Aoyagi, T. Yarita, J. Chromatogr. A 1131 (2006) 285. 